\title{
Waiting for a sign: extended incubation postpones larval stage in the beach spawning California Grunion Leuresthes tenuis (Ayres)
}

\author{
Karen L. M. Martin • Cassadie L. Moravek • \\ Alice J. Walker
}

Received: 1 June 2010 / Accepted: 24 November 2010/Published online: 8 December 2010

(C) The Author(s) 2010. This article is published with open access at Springerlink.com

\begin{abstract}
Unlike most embryos that hatch on a predetermined timetable, California Grunion Leuresthes tenuis can prolong the embryonic period up to three times longer than the time required for hatching readiness. L. tenuis are teleosts that spawn tidally around the highest spring tides of spring and summer, incubating eggs above the water line. Embryos are competent to hatch in 10 days, however they do not hatch until triggered by an environmental cue, agitation in seawater, as the next spring tides rise. This study examined the growth and survival of $L$. tenuis embryos and larvae that were all fertilized on the same day, then triggered to hatch after different durations of incubation, up to 35 days post fertilization. L. tenuis embryos that survive extended incubation had decreased yolk reserves and did not advance appreciably in morphological development, even when incubation time was extended to its upper limit. After extended incubation, length of hatchlings was significantly longer than hatchlings from the primary incubation time. Regardless of the duration of incubation, larvae provided food
\end{abstract}

K. L. M. Martin $(\bowtie) \cdot$ C. L. Moravek · A. J. Walker Natural Science Division, Pepperdine University, 24255 Pacific Coast Highway, Malibu, CA 90263-4321, USA

e-mail: kmartin@pepperdine.edu

K. L. M. Martin

Scripps Institution of Oceanography, UCSD,

La Jolla, CA, USA

e-mail: k9martin@ucsd.edu ad libitum grew rapidly and were not significantly different in length at three weeks post hatch. Dry mass increased over time and was not significantly different between larval groups within any post-hatch age. Larval growth and survival after one additional tidal cycle of incubation are not adversely affected, but longer incubation significantly decreases embryonic and larval survival. Large reproductive output, environmentally cued hatching, and plasticity in incubation duration enable $L$. tenuis to reproduce successfully in the unpredictable sandy intertidal ecosystem.

Keywords Beach · Development · Delayed hatching · Environmentally cued hatching $\cdot$ Teleost .

Atherinopsidae $\cdot$ Larva

\section{Introduction}

Teleost fishes are aquatic by definition (Nelson 2006), yet some species emerge from water to spawn on beaches (reviewed by Martin et al. 2004). Clutches of eggs that are periodically or continuously exposed to air during terrestrial incubation at the water's edge may enjoy advantages (Tewksbury and Conover 1987; Seymour and Bradford 1995), including increased temperatures and oxygen availability (Taylor et al. 1977; Yamahira 1996; Martin and Strathmann 1999) and reduce aquatic predation (Walker 1952; Middaugh et al. 1983). However, embryos in ephemeral ponds or high on marine coastlines may be exposed to novel 
terrestrial predators (Olson 1950; Middaugh et al. 1983; Warkentin and Caldwell 2009), dangerously high temperatures (Nakashima and Taggart 2002), UV radiation (Marco et al. 2001), desiccation (Middaugh et al. 1983; Yamahira 1996; Marco and Blaustein 1999), or human interference (Martin et al 2006; Matsumoto and Martin 2008).

One additional challenge for beach spawning fishes is the hatchling's return to the aquatic or marine environment for larval life. Most organisms hatch on a developmental timetable, into the same environment as the eggs incubate. For terrestrially incubating fish eggs, the return of aquatic conditions may be unpredictable, so hatching on a timetable could result in animals hatching out of water, as happens with beach-spawning capelin Mallotus villosus (Frank and Leggett 1981) and Pseudophryne bibronii frog tadpoles (Geiser and Seymour 1989). As one would expect, the delicate aquatic larvae are profoundly vulnerable and do not survive long under terrestrial conditions.

Egg-enclosed embryos are more resistant to terrestrial conditions than larvae. To avoid the perils of hatching terrestrially, some teleosts and amphibians that spawn at the water's edge are adapted to recognize an environmental cue that signals the return of aquatic conditions (DiMichele and Taylor 1980; Petranka et al. 1982; Bradford and Seymour 1985; Griem and Martin 2000). Use of this environmental cue to trigger hatching permits reproduction in an unpredictable or ephemeral habitat by allowing an individual to remain in a protected, encapsulated form as an egg-enclosed embryo in environments that would be hostile to a gill-breathing larva.

Some of these species have embryos that survive by extending incubation. They can delay hatching until conditions are favorable, essentially until aquatic conditions prevail (Martin 1999), for example with seasonal rainfall (Petranka et al. 1982; Bradford and Seymour 1985) or variable tidal heights (Walker 1952; Moffatt and Thomson 1978; DiMichele and Powers 1984). Once embryos develop to the point of hatching competence, they can hatch fairly quickly at any time the trigger is presented.

One beach spawning teleost, the California grunion Leuresthes tenuis (Atherinopsidae), attracts crowds of admirers as it is carried by surf waves onto shore for reproduction (Martin et al. 2007). Females bury eggs in sand on wave-swept beaches during semilunar high tides in coastal California (Walker 1952; Martin and
Swiderski 2001). The embryos remain above the high tide line during terrestrial incubation, and develop very similarly to aquatic atherinids such as Atherina presbyter (Palmer and Cully 1984) and the atherinomorph Oryzia latipes (Iwamatsu 2004) up to the time of hatching competence (Martin et al. 2009).

Hatching competence in L. tenuis occurs approximately ten days after fertilization (David 1939; Hubbs 1965; Smyder and Martin 2002), at $20^{\circ} \mathrm{C}$. However, the embryos do not hatch until cued by the unique environmental trigger of agitation in seawater (Walker 1952; Griem and Martin 2000; Speer-Blank and Martin 2004). If waves do not reach them on shore, they may remain viable for one or two additional lunar cycles (Darken et al. 1998; Smyder and Martin 2002). Delayed hatching can extend incubation in L. tenuis for up to a month or more after fertilization, depending on temperature. During this time the embryos continue to be alert, and to metabolize at a constant, active rate (Darken et al. 1998).

Like many fish (Taylor 1984), L. tenuis spawn and hatch only during the highest semilunar tides associated with the new and full moons. Eggs spawned at the falling tide of one full or new moon typically hatch during the next rising spring tides, within two weeks, considered the primary hatching time (Walker 1952). California has complex mixed semidiurnal tides, and the highest tide of a new moon is not equal to the highest tide of a full moon of the same month (Walker 1949). If the spring tide of the subsequent full or new moon phase is lower, clutches may not hatch out until the following new or full moon, nearly two weeks later.

The effects on larval growth and survival of extended incubation by delayed hatching have not previously been studied in any fish species. Although the estuarine killifish Fundulus heteroclitus can extend incubation from primary hatching at 9 up to 37 days (DiMichele and Taylor 1980; Martin et al. 2009) its development afterwards, during extended incubation, has not been described (Armstrong and Child 1965). During extended incubation, L. tenuis embryos consume yolk gradually, but if the environmental cue does not occur, the oil droplet disappears and the embryo dies without hatching (Darken et al. 1998; Martin 1999). Late in extended incubation, the embryo may appear alive with a heartbeat and reacting to stimuli, but may not be able to break out 
of the chorion when triggered with the hatching cue (Smyder and Martin 2002), possibly because energy reserves are insufficient for the high degree of activity during hatching.

Extending incubation far longer than the primary period of development may result in some negative effects on growth, survival, and activity for larvae that necessarily use up most of their yolk reserves prior to hatching (Bradford and Seymour 1988; Martin 1999). However, for some amphibians, delaying hatching may improve larval survival and fitness as the larvae emerge at a more advanced stage (Bradford and Seymour 1985; Sih and Moore 1993; Warkentin 1995). Eggs of the aquatic salamander Amphiuma means (Two-toed Amphiuma) can delay hatching for so long that they may develop to the point of gill disappearance during extended incubation, essentially completing the larval period within the egg before hatching (Gunzburger 2003).

Because $L$. tenuis eggs are able to survive extended incubation as much as triple the primary incubation time to hatching competence (Darken et al. 1998; Smyder and Martin 2002), and the hatch date can be easily manipulated (Griem and Martin 2000; SpeerBlank and Martin 2004), growth and survival of $L$. tenuis hatchlings from the same fertilization date, triggered to hatch after three different incubation periods, can readily be compared. Three incubation durations were chosen to correspond to the time of primary hatching competence, and extended incubation periods of double and triple this initial incubation duration. The hypothesis is that larval survival will change with incubation length, and that hatchlings within the primary hatching period will fare better than hatchlings from longer incubation times. Growth and development before and after hatching are compared for the three incubation durations.

\section{Materials and methods}

L. tenuis embryos in eggs were collected by hand from multiple naturally spawned clutches in the sand of Malibu Lagoon (Surfrider) State Beach, Malibu, California USA on mornings following June spawning runs. Clutches typically contain 1000 to 3000 embryos (Walker 1952). Embryo age was verified microscopically according to a staging table (Martin et al. 2009). These naturally fertilized eggs were randomly assigned so that all groups contained embryos from each clutch, and maintained in groups of several hundred in moist native sand in plastic containers in a dark environmental chamber at $18^{\circ} \mathrm{C}$, in the midrange of the natural incubation temperature (David 1939; Hubbs 1965) until hatching. Sand moisture was maintained within normal limits during incubation by spraying the plastic containers lightly with water every other day and keeping them loosely covered to compensate for evaporation (Smyder and Martin 2002). Embryos from the same fertilization date were then triggered to hatch on specific days in order to compare larval growth and survival after incubation times of 10, 15, 20, 25, 30, and 35 days post fertilization.

A group of L. tenuis embryos was hatched at fiveday intervals starting at the initial time of hatching competence, 10 days post fertilization (dpf). A small amount of the incubation sand containing eggs was placed into a container of artificial seawater at the local salinity of $33 \pm 2 \mathrm{ppt}$, and gently swirled by hand for $1 \mathrm{~min}$ (Griem and Martin 2000). Hatching occurred rapidly and the aliquot was swirled again after $5 \mathrm{~min}$ to ensure complete response.

For each of the six post-hatch cohorts, 105 larvae were selected from different clutches to be cultured in aerated seawater. Each cohort was placed in one of six $15 \mathrm{~L}$ glass marine aquaria and held at $18 \pm 1^{\circ} \mathrm{C}$ with an 8:16 light: dark photoperiod for up to 35 days (Reynolds et al. 1976). Seawater at the local salinity of $33 \pm 2$ ppt was partially changed (no more than $300 \mathrm{~mL}$ ) each day to maintain stable salinity and remove wastes, and larvae were fed live nauplii of brine shrimp (Artemia) ad libitum daily.

Larval growth was determined for 5 larvae from each cohort every three days $(\mathrm{N}=10$ per incubation treatment, see below), starting on the day of hatching. Standard length of the larvae was determined by microphotography using NIH Image 1.61 software. Each larva was measured from snout to the tip of the notochord using an ocular micrometer. Afterwards, five larvae were placed on a tared watch glass and dried to constant mass in a drying oven $\left(90^{\circ} \mathrm{C}\right)$ for $36 \mathrm{~h}$ to calculate mean larval dry mass.

Survival was determined by visual assessment of each tank every day. Dead larvae sank to the bottom of the tank and did not respond to stimulation by water current (May 1971). These were counted and removed daily. Survival percentages were calculated by comparing the total number of larvae remaining in 
each age cohort each day, to the total expected if the only losses were caused by the removal of five sample individuals every third day.

Groups were combined for statistical analysis. Larvae from eggs incubated for 10 and 15 days bracket the times eggs would hatch after one semilunar tidal cycle in nature. Compared at each measurement date for length and mass by unpaired Student's t-tests, they did not differ significantly $(\mathrm{P}=$ 0.93 ) so were combined and labeled T1. Lengths and masses of larvae from incubation times of 20 and 25 days also were combined and labeled T2. Similarly, lengths and masses of larvae incubated 30 and 35 days were combined for group T3. Each treatment group, T1, T2 and T3 included two cohorts of 105 larvae each.

Comparisons between larvae at different ages were made at specific days post hatching (dph) between different incubation duration treatments by one-way ANOVA and regression analysis using StatView 4.2, accepting a probability of less than 0.05 as a significant difference. ANOVA data with significant differences were subjected to Fisher's PLSD post hoc tests. Data are reported as means \pm standard error.

\section{Results}

L. tenuis larvae from the three different incubation times were significantly different in initial length at hatching (ANOVA; $\left._{(2,27)}=10.99, \mathrm{P}<0.001\right)$. T1 hatchlings were significantly shorter at $6.76 \pm 0.16 \mathrm{~mm}$ than $7.63 \pm$ $0.10 \mathrm{~mm}$ for $\mathrm{T} 2$ larvae and $7.50 \pm 0.15 \mathrm{~mm}$ for $\mathrm{T} 3$ larvae (Fig. 1). However, by post-hatch day 10, T1 larvae were not significantly different in length from $\mathrm{T} 2$ larvae of the same post-hatch age, whereas T3 larvae were significantly shorter at their post-hatch day 10 (ANOVA; $\left.\mathrm{F}_{(2,27)}=13.48, \mathrm{P}<0.0001\right)$. Lengths of surviving larvae from all three incubation times were not significantly different from one another at larval days 22 and 31, even though their actual chronological ages were several weeks apart. For T3 larvae, the last day of measurement, Day 28, was used for comparison at Day 31.

Significant linear regressions of larval mean lengths were calculated for each incubation cohort. T1 larvae grew $0.22 \mathrm{~mm} \mathrm{day}^{-1}\left(y=7.46+0.22 \times, r^{2}=0.92\right)$. Both T2 and T3 larvae grew $0.20 \mathrm{~mm}^{-1 a y}{ }^{-1}$ (T-2: $y=7.86+$ $0.20 \times, r^{2}=0.94$; T-3: $y=7.04+0.20 \times, r^{2}=0.96$ ).

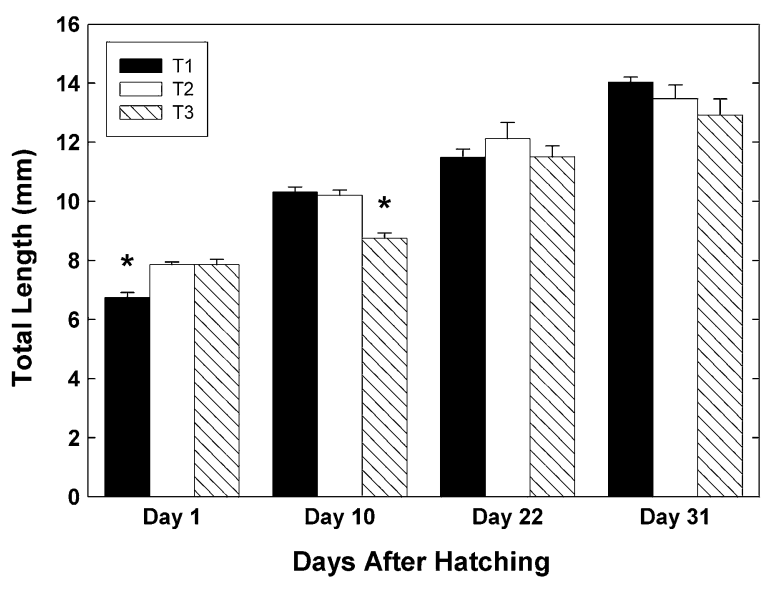

Fig. 1 Total length for L. tenuis larvae at four different days after the hatch date. Embryos were hatched at primary (T1), double (T2) and triple (T3) the primary incubation times. For T3 larvae, measurements were taken at Day 28, the last day any of this cohort survived. Asterisks indicate significant differences within one post-hatch age between larvae of different durations of incubation. $N=10$ for each group, mean $\pm \mathrm{SE}$

Larval dry mass increased over time, but dry masses of $L$. tenuis larvae at any specific post-hatch age did not significantly differ between the different incubation times (ANOVA, $\mathrm{F}_{(1,16)}=0.24, P=0.88$ ). The increase in dry mass after hatching was highly variable, but there was no significant difference between mean masses of larvae from different incubation times within each post-hatch age. Combined means produced a significant linear regression of growth over time, $y=0.0006 \mathrm{x}+0.0009, r^{2}=0.91$, with a steady increase in dry mass each week.

Survival differences between hatchlings from different incubation durations appeared early in larval life (Fig. 2). At least $80 \%$ of $\mathrm{T} 1$ and $\mathrm{T} 2$ larvae survived for the four weeks of the experiment, but T3 larval survival fell below $80 \%$ ten days after hatching, and no T3 larvae survived to four weeks after hatching. Survival of T3 larvae was significantly lower than survival of $\mathrm{T} 1$ and $\mathrm{T} 2$ larvae over the course of the experiment (ANOVA on arc sine transformed data, $F=360.8, P<0.001)$ as compared at $20 \mathrm{dph}(P<0.01), 28 \mathrm{dph}(P<0.0001)$ and $35 \mathrm{dph}$ $(P<0.001)$.

\section{Discussion}

L. tenuis embryos did not advance appreciably in morphological development after reaching hatching 


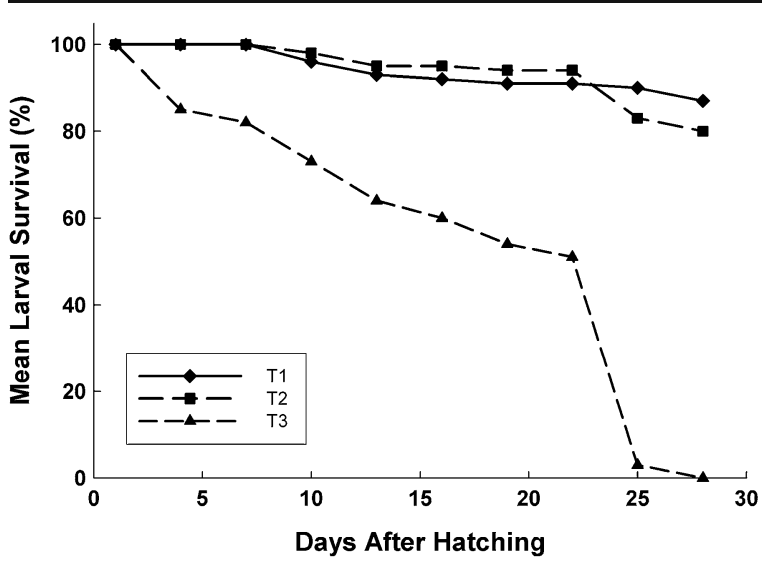

Fig. 2 Survival of L. tenuis larvae hatched after primary (T1), double (T2) and triple (T3) the primary incubation times. At least $80 \%$ of T1 and T2 larvae survived 4 weeks after hatching, but T3 larvae had significantly lower survival, below $80 \%$ within ten days after hatching

competence, and survived extended incubation while depleting energy reserves. Hatchlings after extended incubation did not appear to be adversely affected in larval growth, even when the incubation period was extended almost to its upper limit. This arrested development is quite different from the situation in amphibians that delay hatching while continuing to progress through developmental stages (Geiser and Seymour 1989; Sih and Moore 1993; Gunzburger 2003).

L. tenuis that prolonged the embryonic period past the time of hatching readiness were remarkably consistent in growth after hatching into larvae. Longer incubation resulted in greater initial hatchling length (Fig. 1), but length measurements for all groups converged within 3 weeks post-hatching. All L. tenuis larvae given food ad libitum and stable environmental conditions grew at a steady rate, no matter the duration of incubation, that was comparable to the growth in length of $0.22 \mathrm{~mm}$ per day previously reported for L. tenuis larvae (Vásquez Yeomans and Sosa-Cordero 1992). In a previous study, L. tenuis larvae that were hatched at primary competence after incubating in temperatures that bracket their tolerance from 14 to $29^{\circ} \mathrm{C}$ (Hubbs 1965), enough to cause a week difference in development to primary hatching competence (Smyder and Martin 2002), still had the same larval growth rates when cultured at a single rearing temperature (Ehrlich and Farris 1971). With this growth rate, larvae would reach adult size and be ready to spawn within one year (Walker 1949).
L. tenuis larvae from different incubation times were not significantly different in dry mass at similar post-hatch ages, although only the most robust $\mathrm{T} 3$ larvae survived extended incubation and were able to grow. Measurements were highly variable, and dry mass is probably not a particularly reliable metric for larval growth (Fuiman et al. 1998).

L. tenuis hatch with open mouths ready to feed, and the yolk sac disappears within 4 days after hatching (May 1971; Reynolds et al. 1976). In fishes, embryos normally hatch when the digestive system is mature or nearly so (Shardo 1995). When May (1971) withheld food, L. tenuis larvae did not increase in mass until they were fed, and mean larval length in his study actually decreased over time. Since fewer than $10 \%$ of his unfed larvae survived to 15 days post hatch, the smaller mean size may reflect slightly better survival of smaller larvae, rather than a true decrease in length. None of May's (1971) larvae survived longer than 16 days without feeding, a total of $26 \mathrm{dpf}$, similar to the chronological age dpf at hatching for T2 larvae in the present study. T3 embryos within the egg survived up to $35 \mathrm{dpf}$ without exogenous feeding, and upon hatching, began growing at the same rate as T1 larvae that had not experienced extended incubation. These studies indicate remarkable resilience and plasticity in L. tenuis growth and development, both before and after hatching.

Extended incubation in L. tenuis is fueled by a large demersal egg with a substantial yolk (Moffatt and Thomson 1978). Atheriniform fishes in general have large, demersal eggs (May 1971; Rosen and Parenti 1981 ), but the mean egg volume of $L$. tenuis is $310 \%$ greater than the eggs of its congener, Leuresthes sardina, the Gulf Grunion (Moffatt and Thomson 1978). On the other hand, L. tenuis spawning in San Francisco Bay were significantly smaller than conspecifics from southern California, and this population produced significantly smaller eggs (Johnson et al. 2009; Martin et al. 2009).

L. sardina spawns on beaches of the Gulf of California, a large embayment. Moffatt and Thomson (1978) suggested this species may have less need to provision the eggs because of the much more consistent heights of tidal excursions than on the outer coast of California, perhaps resulting in less likelihood of a need for extended incubation. However, differences in tidal cycles may be mitigated by active choice of oviposition sites by females. Further study is needed 
to compare the effects of differences in maternal provisioning of embryos for these two species in terms of delayed hatching and extended incubation.

With extended incubation, reductions in energy reserves may diminish hatchling condition in subtle ways, even under ideal laboratory conditions with no predators and food provided ad libitum. It is likely that $L$. tenuis larvae that undergo extended incubation times have decreased tolerance for larval starvation, although the present study did not pose this challenge. Differences in survival were apparent between $L$. tenuis within 10 days post hatch for $\mathrm{T} 3$ larvae, and only $50 \%$ survived three weeks (Fig. 2). However, T2 larvae survived equally well as T1 for the duration of the experiment. If cohorts from different incubation durations were in competition with one another under more natural conditions, additional differences in fitness or performance are likely to emerge.

Only embryos that survived the period of extended incubation could be used as subjects for the larval experiments, and by 30 days of incubation, fewer than $50 \%$ of embryos are still able to hatch and emerge from the chorion (Smyder and Martin 2002), so this initial cost adds to the decrease in survival of T3 individuals. Although L. tenuis embryos are able to hatch at any time following initial competence, in nature, those that do not hatch after one tidal cycle would most likely have to extend incubation until the spring tides of the following cycle (Walker 1952; Moffatt and Thomson 1978; Smyder and Martin 2002).

Detailed examination of embryo morphology was not a focus of the present study. However, no major advances in developmental stage between hatchlings of different incubation times were observed in the present study, except for increased total length and greater pigmentation of melanophores for older hatchlings. David (1939) noted no difference between $L$. tenuis larvae hatched after 8 days and those hatched after incubating 14 days, and Darken et al. (1998) reported that L. tenuis hatchlings did not differ markedly between embryos with incubation times ranging from 10 to 21 days except for some increased pigmentation. Moravek and Martin (in preparation) have noted some morphological developmental changes in L. tenuis embryos during extended incubation, but these are isolated features developing more slowly and out of synchrony with normal larval development. In short, during extended incubation, L. tenuis embryos do not undergo the profound changes that $L$. tenuis of the same chronological age do as larvae (Vásquez Yeomans and Sosa-Cordero 1992; Watson 1996; Vásquez-Yeomans et al 2000; Valdéz-Moreno and Vásquez-Yeomans 2001).

Metamorphosis normally occurs at 40 days post hatch, or $50 \mathrm{dpf}$ (Vásquez Yeomans and Sosa-Cordero 1992). The present study was terminated before larvae entered metamorphosis but it appears that after hatching, larval development occurs along the same pathway and with the same timing for both primary and extended incubation L. tenuis. In effect, it appears that most of the initial stages of larval life in L. tenuis are simply delayed as long as hatching is delayed. In L. tenuis embryos, metabolism increases during incubation until the time of hatching competence, then it stabilizes and remains steady well into the extended incubation period (Darken et al. 1998). This stable-but not depressed-metabolic rate permits alertness and the muscular activity necessary for rapid hatching when the environmental cue arrives, conserving energy rather than using it for additional growth and differentiation until the unpredictable time of hatching and exogenous feeding begins.

Clutches of L. tenuis embryos that are developed to the point of hatching competence but still within the eggs are occasionally found near clutches of newly fertilized embryos in the field (personal observation), indicating that extended incubation occurs in nature, and that females select oviposition tidal heights. Thus embryos corresponding to the time of primary hatching competence could be present with those of extended incubation, and all could hatch at the same time. It is possible that the small advantages of $\mathrm{T} 1$ larvae seen in this study would be magnified under natural conditions, when competition for food may be more intense and predators are present. Extending incubation for one additional semilunar tidal cycle does not appreciably change larval survival, but extending incubation to a greater extent decreases survival for both embryos and larvae.

Environmentally cued hatching enables survival of terrestrial L. tenuis embryos until they can become aquatic larvae, making reproduction in the sandy intertidal zone possible. Provisioning eggs with sufficient yolk to extend incubation for one additional semilunar tidal cycle increases the likelihood that at least some offspring will survive to hatch in this 
environment where tidal heights and wave conditions vary. Yolk supplies in this species apparently are sufficient to maintain the embryo at the point of hatching readiness for double or triple the normal incubation time, but exogenous feeding is necessary for additional growth and development. Even with inherent uncertainties, the benefits of terrestrial incubation of $L$. tenuis embryos and environmentally cued hatching, coupled with the ability to extend incubation to double or triple its primary length, provide an effective early life history strategy for this unique beach spawning fish.

Acknowledgments M Schaadt, Cabrillo Marine Aquarium provided field and laboratory assistance. M Horn, D Martin, T Vandergon, L Kats and S Warford shared helpful comments, and D Green assisted with figures. Embryos and larvae were maintained according to the guidelines and supervision of Pepperdine University IACUC. This study was supported by the US National Science Foundation, IBN 99-87543, the National Marine Fisheries Service and NOAA, contract \#WRAD 8-819, and the National Geographic Society CRE 8105-07. Special thanks to the Lost Hills Sheriffs Department, Los Angeles County Lifeguards, and California State Parks for assistance with fieldwork.

Open Access This article is distributed under the terms of the Creative Commons Attribution Noncommercial License which permits any noncommercial use, distribution, and reproduction in any medium, provided the original author(s) and source are credited.

\section{References}

Armstrong PB, Child JS (1965) Stages in the normal development of Fundulus heteroclitus. Biol Bull 128:143-168

Bradford DF, Seymour RS (1985) Energy conservation during the delayed-hatching period in the frog Pseudophryne bibroni. Physiol Zool 58:491-496

Bradford DF, Seymour RS (1988) Influence of water potential on growth and survival of the embryo, and gas conductance of the egg, in a terrestrial breeding frog, Pseudophryne bibroni. Physiol Zool 61:470-474

Darken RS, Martin KLM, Fisher MC (1998) Metabolism during delayed hatching in terrestrial eggs of a marine fish, the grunion Leuresthes tenuis. Physiol Zool 71:400406

David LR (1939) Embryonic and early larval stages of the grunion, Leuresthes tenuis, and of the sculpin, Scorpaena guttata. Copeia 1939:75-80

DiMichele L, Taylor M (1980) The environmental control of hatching in Fundulus heteroclitus. J Exp Zool 214:181187

DiMichele L, Powers DA (1984) The relationship between oxygen consumption rate and hatching in Fundulus heteroclitus. Physiol Zool 57:46-51
Ehrlich KF, Farris DA (1971) Some influences of temperature on the development of the grunion, Leuresthes tenuis. Calif Fish Game 57:58-68

Frank KT, Leggett WC (1981) Wind regulation of emergence times and early larval survival in capelin (Mallotus villosus). Can J Fish Aquat Sci 38:215-223

Fuiman LA, Poling KR, Higgs DM (1998) Quantifying developmental progress for comparative studies of larval fishes. Copeia 1998:602-611

Geiser F, Seymour RS (1989) Influence of temperature and water potential on survival of hatched, terrestrial larvae of the frog Pseudophryne bibronii. Copeia 1989:207-209

Griem JN, Martin KLM (2000) Wave action: the environmental trigger for hatching in the California grunion, Leuresthes tenuis. Mar Biol 137:177-181

Gunzburger MS (2003) Evaluation of the hatching trigger and larval ecology of the salamander Amphiuma means. Herpetologica 59:459-468

Hubbs C (1965) Developmental temperature tolerance and rates of four southern California fishes, Fundulus parvipinnis, Atherinops affinis, Leuresthes tenuis, and Hypsoblennius sp. Calif Fish Game 51:113-122

Iwamatsu T (2004) Stages of normal development of the medaka Oryzias latipes. Mech Dev 121:605-618

Johnson PB, Martin KL, Vandergon TL, Honeycutt RL, Burton RS, Fry A (2009) Microsatellite and mitochondrial genetic comparisons between northern and southern populations of California Grunion Leuresthes tenuis. Copeia 2009:467-476

Marco A, Blaustein AR (1999) Egg gelatinous matrix protects Ambystoma gracile embryos from prolonged exposure to air. Herpetol J 8:207-211

Marco A, Lizana M, Alvarez A, Blaustein AR (2001) Eggwrapping behaviour protects newt embryos from UV radiation. Anim Behav 61:1-6

Martin KLM (1999) Ready and waiting: delayed hatching and extended incubation of anamniotic vertebrate terrestrial eggs. Amer Zool 39:279-288

Martin KLM, Strathmann RA (1999) Aquatic organisms, terrestrial eggs: early development at the water's edge. Amer Zool 39:215-217

Martin KLM, Swiderski DL (2001) Beach spawning in fishes: phylogenetic tests of hypotheses. Amer Zool 41:526-537

Martin KLM, Van Winkle RC, Drais JE, Lakisic H (2004) Beach spawning fishes, terrestrial eggs, and air breathing. Physiol Biochem Zool 77:750-759

Martin K, Speer-Blank T, Pommerening R, Flannery J, Carpenter K (2006) Does beach grooming harm grunion eggs? Shore Beach 74:17-22

Martin K, Staines A, Studer M, Stivers C, Moravek C, Johnson P, Flannery J (2007) Grunion Greeters in California: Beach spawning fish, coastal stewardship, beach management and ecotourism. Proc 5th International Coastal \& Marine Tourism Congress: Balancing marine tourism, development and sustainability. In: Lück M, Gräupl A, Auyong J, Miller ML, Orams MB (eds). Auckland, NZ: New Zealand Tourism Res Inst., pp 73-86

Martin KL, Moravek CL, Flannery JA (2009) Embryonic staging series for the beach spawning, terrestrially incubating California grunion Leuresthes tenuis (Ayres 1860) with comparisons to other Atherinomorpha. J Fish Biol 75:17-38 
Matsumoto JK, Martin KLM (2008) Lethal and sublethal effects of altered sand salinity on embryos of beachspawning California Grunion. Copeia 2008:483-490

May RC (1971) Effects of delayed initial feeding on larvae of the grunion, Leuresthes tenuis (Ayres). Fish Bull 69:411-425

Middaugh DP, Kohl HW, Burnett LE (1983) Concurrent measurement of intertidal environmental variables and embryo survival for the California grunion, Leuresthes tenuis, and the Atlantic silverside, Menidia menidia (Pisces: Atherinidae). Calif Fish Game 69:89-96

Moffatt NM, Thomson DA (1978) Tidal influence on the evolution of egg size in the grunions (Leuresthes, Atherinidae). Environ Biol Fish 3:267-273

Nakashima BS, Taggart CT (2002) Is beach-spawning success for capelin, Mallotus villosus (Muller), a function of the beach? ICES J Mar Sci 59:897-908

Nelson JS (2006) Fishes of the world. John Wiley \& Sons, Inc.

Olson AC (1950) Ground squirrels and horned larks as predators upon grunion eggs. Calif Fish Game 36:323-327

Palmer CJ, Cully MB (1984) The eggs and early life history of the sandsmelt, Atherina presbyter Cuvier. J Fish Biol 24:537-544

Petranka JW, Just JJ, Crawford EC (1982) Hatching of amphibian eggs: the physiological trigger. Science 217:257-259

Reynolds WW, Thomson DA, Casterlin ME (1976) Temperature and salinity tolerances of larval California grunion, Leuresthes tenuis (Ayres): a comparison with gulf grunion, L. sardina (Jenkins and Evermann). J Exp Mar Biol Ecol 24:73-82

Rosen DE, Parenti LR (1981) Relationships of Oryzias, and the groups of atherinomorph fishes. Amer Mus Nov 2719:1-25

Seymour RS, Bradford DF (1995) Respiration of amphibian eggs. Physiol Zool 68:1-25

Shardo JD (1995) Comparative embryology of teleostean fishes. I. Development and staging of the American shad, Alosa sapidissima (Wilson, 1811). J Morphol 225:125-167

Sih A, Moore RD (1993) Delayed hatching of salamander eggs in response to enhanced larval predation risk. Amer Nat 142:947-960

Smyder EA, Martin KLM (2002) Temperature effects on egg survival and hatching during the extended incubation period of the California grunion, Leuresthes tenuis. Copeia 2002:313-320

Speer-Blank T, Martin KLM (2004) Hatching events in the California Grunion, Leuresthes tenuis. Copeia 2004:21-27

Taylor MH (1984) Lunar synchronization of fish reproduction. Trans Amer Fish Soc 113:484-493

Taylor MH, DiMichele L, Leach GJ (1977) Egg stranding in the life cycle of the mummichog, Fundulus heteroclitus (Pisces: Cyprinodontidae). Copeia 1977:291-297

Tewksbury HT, Conover DO (1987) Adaptive significance of intertidal egg deposition in the Atlantic silverside Menidia menidia. Copeia 1987:76-83

Valdéz-Moreno M, Vásquez-Yeomans L (2001) Description of the osteological development of the caudal complex of laboratory-reared larvae of grunion Leuresthes tenuis (Ayres, 1860). Bull Mar Sci 68(2):351-356

Vásquez Yeomans L, Sosa-Cordero E (1992) Culture of grunion Leuresthes tenuis (Ayres) larvae to metamorphosis, in the laboratory. Cienc Mar 18:1-18

Vásquez-Yeomans L, Valdéz-Moreno M, Richards WJ (2000) Description of laboratory reared larvae of California Grunion and comparisons with larvae of topsmelt and jacksmelt. Calif Fish Game 86:175-185

Walker BW (1949) The periodicity of spawning by the grunion, Leuresthes tenuis, an atherine fish. PhD Thesis, Univ Calif Los Angeles

Walker BW (1952) A guide to the grunion. Calif Fish Game 3:409-420

Warkentin KM (1995) Adaptive plasticity in hatching age: a response to predation risk trade-offs. Proc Nat Acad Sci USA 92:3507-3510

Warkentin KM, Caldwell MS (2009) Assessing risk: embryos, information, and escape hatching. In: Dukas R, Ratcliffe JM (eds) Cognitive ecology II: the evolutionary ecology of information processing and decision-making. University of Chicago Press, Chicago, pp 177-200

Watson W (1996) Atheriniformes. In: Moser HG (ed) The early stages of fishes in the California current region. California Coop. Oceanic Fish. Invest. Atlas 33, pp 608-619

Yamahira K (1996) The role of intertidal egg deposition on survival of the puffer, Takifugu niphobles (Jordan et Snyder), embryos. J Exp Mar Biol Ecol 198:291-306 